\title{
Recensión del libro: Valverde, J. (coord.) (2015). El Proyecto de Educación Digital en un centro educativo. Guía para su elaboración y desarrollo. Madrid: Síntesis
}

\author{
Pedro Antonio García Tudela \\ Universidad de Murcia (España) \\ pedroantonio.garcia4@um.es
}

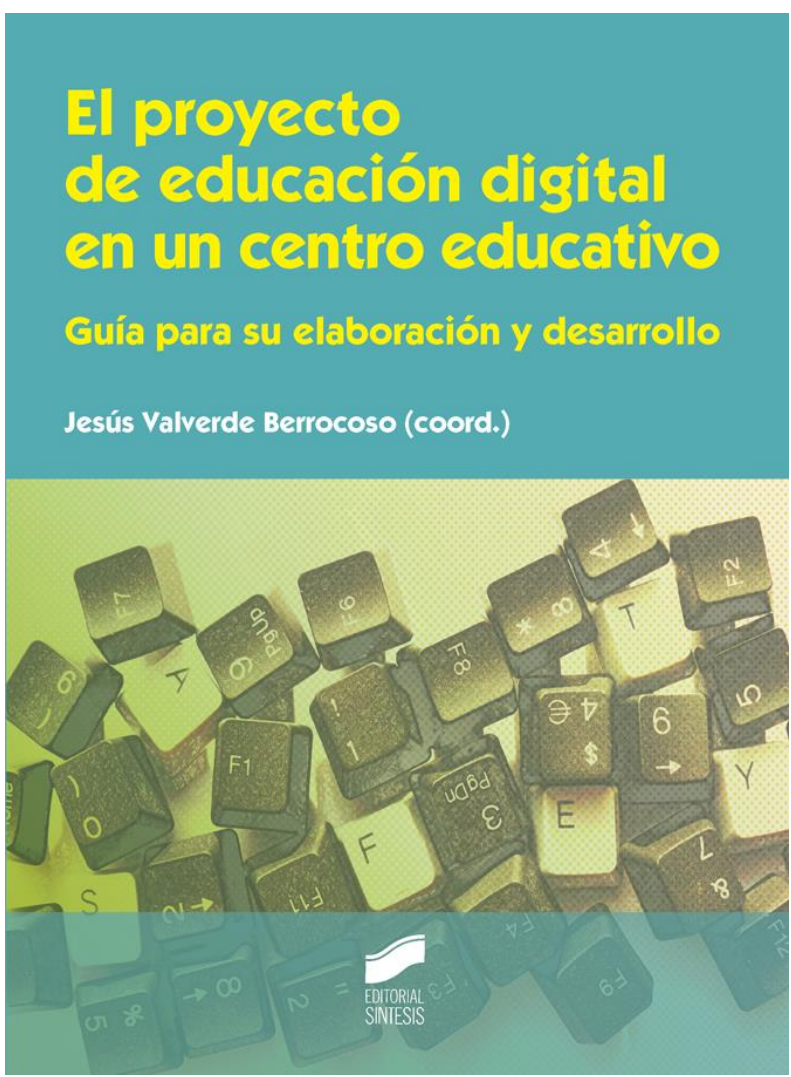

El concepto de innovación pedagógica referido a la tecnología educativa; el enfoque didáctico desde su adjetivación de digital; los resultados de dos investigaciones nacionales; entre otras razones de gran interés son las causas principales que conducen a Jesús Valverde Berrocoso a coordinar la obra "el proyecto de educación digital en un centro educativo".

La incorporación e implementación de praxis docentes cuyo eje vertebrador valore el uso de las TIC es un hecho irrefutable, pues existen aportaciones clásicas pedagógicas como la de la escuela de Decroly (S.XIX) que señaló que se ha de educar para la vida a través de la vida misma. Ello evidencia la utilización de la tecnología en el contexto educativo, puesto que se ha de reconocer que los dispositivos tecnológicos comparten nuestro escenario más personal y social.

La alusión recién explicitada es núcleo de diversas propuestas didácticas y programas escolares que no siempre garantizan unas óptimas prácticas docentes con TIC (estrechamiento del abismo entre los dispositivos digitales y su uso como recurso educativo), principalmente debido a una nefasta formación profesional pedagógica sobre el uso eficaz de las herramientas tecnológicas, la cual debe ser brindada por la Administración como respuesta a las demandas reales del profesorado.

El libro reseñado adquiere el compromiso de ofrecer una solución al problema planteado, ya que presenta la guía para la elaboración y el desarrollo de un Proyecto de Educación Digital (PED a partir de ahora). Los autores colaboradores y el coordinador muestran diversos aspectos a tener en cuenta para lograr la mejora de la calidad del proceso de enseñanza-aprendizaje a partir de la redefinición del rol de las TIC. Desde la introducción se afirma que el PED debe de estar coordinado con las políticas educativas, pero en ningún momento subordinado, ya que para su óptima elaboración y puesta en práctica ha de destacar la autonomía que posee el centro escolar. 
Los siete capítulos que estructuran el libro sustentan la idea de que un adecuado uso de las TIC beneficia las buenas prácticas docentes, pero nunca convierten las impropias en excelentes. En el primer capítulo, coincidente con la introducción, se alude a la justificación de lo tratado. Además, se invita a la colaboración profesional, la búsqueda de documentación y la reflexión crítica para responder de manera pertinente a la "invasión" tecnológica que se está produciendo en el contexto escolar.

El segundo capítulo actúa como base de los restantes, pues consiste en un análisis de los niveles de concreción política educativa en cuanto a la integración de las TIC: micro (nivel de responsabilidad individual [actitudes, habilidades, etc.]), meso (responsabilidad institucional [infraestructura, liderazgo, etc.]) y macro (responsabilidad de la administración [objetivos, dotación, etc.]). También concede la posibilidad de extraer relevantes reflexiones en cuanto al modelo vertical "arriba-abajo" que existe entre la macro y micropolítica educativa TIC. Cabe destacar que debería invertirse el binomio propuesto, ya que el éxito de prácticas escolares de integración de las TIC reside en las micropolíticas, a partir de las cuales se deben de realizar las propuestas y mejoras que han de afrontar y responder a nivel macro.

El concepto de "centros educativos e-competentes" es descrito en el tercer capítulo, el mismo está muy arraigado a la perspectiva del cambio (school improvement perspective), ya que el principal término descrito persigue provocar el cambio efectivo en la docencia a través del uso de las TIC. Para alcanzar dicha meta se debe valorar el rol del coordinador TIC; el PED con implicaciones a corto y medio plazo; la evaluación; el liderazgo, entre otros aspectos especificados en el texto.

Además, de manera acentuada y presentando diversos modelos, se hace alusión a la importancia de la autonomía escolar. Hecho que denota el matiz de no subordinación ante las macropolíticas y permite la concreción oportuna al contexto real.

El cuarto capítulo recoge una frase que resume la idea y finalidad del mismo: "permanecer parados es retroceder". La razón de ello es debido a que el PED es el producto que surge tras la combinación de diferentes creencias, actitudes, infraestructuras, recursos (materiales y humanos), etc. Por lo tanto, conlleva unos procesos de deliberación y apertura a la innovación que han de propiciar un cambio de perspectiva sobre la visión de la Tecnología Digital (TD a partir de ahora), ya que la misma ha de favorecer la digitalización de la educación. Los autores puntualizan que el hecho explicitado no consiste en la aislada introducción de dispositivos en el aula, sino en la modificación del entorno de enseñanza-aprendizaje en beneficio del desarrollo de las competencias del siglo XXI (ciudadano crítico, colaborativo y creativo) en una sociedad veloz y en red.

Technology Planning in Schools (TPS) de Bélgica; Four in Balance de Holanda; Self-review Framework (SRF) de Reino Unido y e-Learning Plan de Irlanda son los cuatro modelos europeos presentados en el quinto capítulo para ofrecer distintas visiones de cómo planificar un PED. De la lectura exhaustiva de los mismos se obtienen diversos puntos coincidentes, siendo algunos de ellos: no se trata la competencia digital como un fin en sí misma, sino como uso de la misma para el proceso de E-A; el proceso de planificación presenta un carácter autoevaluador de creencias docentes, metodología empleada, infraestructuras, etc.; El liderazgo pedagógico posee una gran relevancia orientadora y organizadora; entre otros más. Además, la reflexión de base es que el proceso de elaboración del PED es más relevante que el producto final que se obtenga (documento escrito físico o digital; vídeo; infografía, etc.).

El sexto capítulo propone el proceso evaluativo del PED, entendiéndose este como un proceso formativo que ofrece la información pertinente sobre la acción educativa e innovadora desempeñada. Destacar que de esta manera se podría posibilitar el replanteamiento constante del documento implementado y garantizar así su relación con el contexto real. Como consecuencia a dichas características se propone la denominación de este proceso como: "evaluación de la innovación en movimiento". Además, los autores plantean diversos proyectos, modelos y enfoques que proponen criterios e indicadores que pueden favorecer el diseño de la evaluación del proyecto de cualquier centro escolar. 
La reflexión sobre una sociedad y educación abierta es el tema encargado de cerrar la presente obra. De manera pormenorizada se presenta el concepto de Recursos Educativos Abiertos (REA u OER), motivando a su uso y creación desde una perspectiva de e-learning para de esta forma superar la latente brecha de aprendizaje. Al fin perseguido lo complementan una serie de desafíos y principios a tener en cuenta, los cuales son presentados junto a diversos ejemplos (OpenLearn, Wikiwijs, etc.) y sistemas como "CORRE" para favorecer la introducción de dichos recursos al sistema educativo. La principal intención del autor con este capítulo es lograr que el lector reflexione sobre la relevancia de insertar el PED en el actual contexto digital abierto, brindando de esta forma beneficios para toda la comunidad educativa de una manera recíproca.

Para concluir, e independientemente de la carencia formativa sobre el rol de las familias en el proceso de elaboración y puesta en práctica del proyecto, se ha de puntualizar que el distinguido filósofo Auguste Compte señaló: "el amor como principio, el orden como base, el progreso como fin". De manera indudable, dicha cita podría ser la página de apertura de la obra reseñada, puesto que el coordinador y los autores del libro consiguen ofrecer una óptima guía para el diseño, implementación, evaluación y difusión de un PED. Invitando asimismo a la reflexión sustentada en múltiples ejemplos de cómo enfocarlo desde una perspectiva abierta, democrática, digital y transparente.

\section{INFORMACIÓN SOBRE EL AUTOR}

\section{Pedro Antonio García Tudela \\ Universidad de Murcia}

Pedro Antonio García Tudela posee el título de Grado en Educación Primaria con mención en Educación Intercultural y Dificultades de Aprendizaje por la Universidad de Murcia. Actualmente cursa el Máster de Investigación e Innovación en Educación Primaria e Infantil en dicha Institución. Además, es colaborador en el departamento de DOE (Didáctica y Organización Escolar), concretamente en el grupo de trabajo GITE (Grupo de Investigación de Tecnología Educativa), durante el presente curso está desarrollando un proyecto sobre aplicaciones digitales e inclusión.

Se ha de señalar que es autor de diversos artículos de investigación y participante en numerosos congresos de carácter nacional e internacional que versan sobre temas tales como: metodologías activas, una de sus últimas propuestas que más impacto ha tenido en las Redes Sociales ha sido la escape room didáctica "el compromiso de la galaxia Deitania" (https://goo.gl/iM4bei); inclusión educativa y TIC, entre otras.

Gran parte de sus implicaciones didácticas se pueden seguir a través de sus redes sociales: @Pe_Garcia2 (Twitter).

Los textos publicados en esta revista están sujetos a una licencia de Reconocimiento 4.0 España de Creative Commons. Puede copiarlos, distribuirlos, comunicarlos públicamente y hacer obras derivadas siempre que reconozca los créditos de las obras (autoría, nombre de la revista, institución editora) de la manera especificada por los autores o por la revista. La licencia completa se puede consultar en:Licencia Creative Commons Atribución-NoComercial-Compartir por igual 4.0 Internacional. 